Benedikt: Ueber Nononitrobrenzkatechin. 455

welcher das dentsche Laboratorium zum ersten der Welt machte. Indessen dürfen wir nicht auf unsern Iorbeeren ruhen, wir können gewiss sein, dass dasselbe England, welches jetzt ruhig zuschaut, wie wir seinen Theer in Farben verwandeln und zu hohem Preise an das Ausland verkaufen, nicht zögern wird die Quelle zu verschliessen (?), sowie es deutscher Arbeit gelungen ist, alle technischen Schwierigkeiten zu beseitigen und die Fabrikation der Farben zu einer Vollkommenheit zu entwickeln, wie sie in der Soda und Schwefelsäureindustrie thatsächlich vorhanden ist. Der einzige Schutz dagegen besteht in unablässiger Arbeit, eine Entdeckung muss sich an die andere reihen und nie darf sich Deutschland auf diesem Gebiete der ruhigen Ausbeutung früherer Erfindungen hingeben.

Der Leser, welcher vorstehende Rede aufmerksam durchgegangen ist, und sich bemüht hat, dem Ideengange $z u$ folgen, wird mir darin beipflichten, dass die Rede mehr geträumt, als durchdacht, und dass sie eines deutschen Gelehrten nicht würdig ist.

Leipzig, 2. December 1878.

\title{
Ueber Mononitrobrenzkatechin;
}

von

\section{Dr. Rudolf Benedikt ${ }^{1}$.}

Löst man je 4 Grm. Brenzkatechin und $20 \mathrm{Grm}$. käufliches salpetrigsaures $\mathrm{Kali}$ in $150 \mathrm{CC}$. Wasser auf und fügt nun verdünnte Schwefelsäure so lange hinzu, bis kein Aufbrausen mehr stattfindet, so hat sich die Flüssigkeit dunkel-

1) Aus dem Sitzungsberichte der Wiener Academie der Wissenschaft, mathem.-naturwissensch. Classe, 76, 812. 
456 Benedikt: Ueber Mononitrobrenzkatechin.

braunroth gefärbt. Man schüttelt möglichst rasch mit dem gleichen Volumen Aether aus. Dieser hinterlässt beim Abdestilliren einen reichlichen, krystallinisch erstarrenden, dunkel gefärbten Rückstand. Hat man eine grössere Partie des Rohproductes gesammelt, so zieht man dasselbe mit kochendem Benzol aus und giesst von dem ungelöst gebliebenen durch ein Filter ab. Aus dem Filtrate setzen sich beim Erkalten gelbe Krusten an die Wände des Krystallisirgefässes ab. Die Mutterlaugen werden zu den folgenden Auskochungen verwendet, die so lange fortgesetzt werden, als sich beim Erkalten noch beträchtliche Mengen des gelben Körpers ausscheiden.

Derselbe wird durch nochmaliges Umkrystallisiren aus Benzol vollständig rein erhalten. Er konnte seiner Bildungsweise nach entweder ein Nitroso- oder ein Nitrokörper sein. Darüber gab die Elementaranalyse sichern Aufschluss :

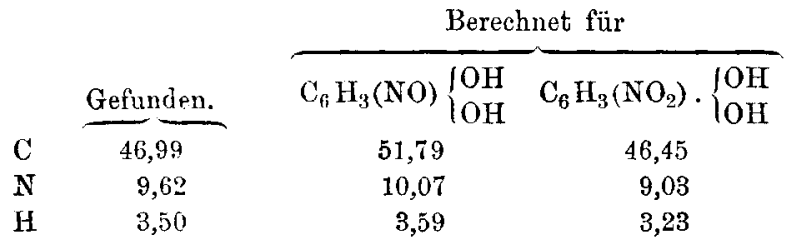

Die neue Verbindung ist somit ein Mononitrobrenzkatechin. Es bildet sehr kleine, wollige Nadeln, ist in Wasser, Alkohol und Aether leicht, in Benzol dagegen schwer löslich. Sein Sehmelzpunkt liegt bei $157^{\circ}$ (uncorr.), bei weiterem Erhitzen zersetzt es sich, um endlich mit russender Flamme unter Hinterlassung von viel Kohle zu verbrennen.

Besonders auffallend ist seine Eigenschaft, sich in Kalilauge mit prächtigster Purpurfarbe zu lösen, eine Reaction, die so empfindlich ist, dass das Mononitrobrenzkatechin einen vortrefflichen Indicator für Titrirungen abgiebt.

Salpetersäure wirkt darauf sehr heftig ein und verbrennt es unter stiirmischer Gasentwicklung. 
Benedikt: Ueber Mononitrobrenzkatechin. 457

Barytsalz. Ein neutrales Barytsalz von der Formel

$$
\mathrm{C}_{6} \mathrm{H}_{3} \cdot \mathrm{NO}_{2} \cdot\left\{\begin{array}{l}
\mathrm{O} \\
\mathrm{O}
\end{array}>\mathrm{Ba}+3 \mathrm{H}_{2} \mathrm{O}\right.
$$

kann leicht erhalten werden. Zu einer verdünnten wässrigen Lösung des Nitrokörpers fügt man Barytwasser so lange hinzu, bis die Flüssigkeit eine schön rothe Farbe angenommen hat. Nach einigen Secunden scheidet sich das Salz in Form dunkelrother Blättchen vom schönsten Metallglanze aus. Es ist selbst in siedendem Wasser sehr schwer löslich.

Beim Trocknen auf $130^{\circ}$ verliert das Salz sein Krystallwasser und wird dunkelgrün, ohne jedoch etwas von seinem Glanze einzubüssen.

Das saure Barytsalz ist in Wasser viel leichter löslich und konnte bis jetzt nicht krystallisirt erhalten werden.

Monoamidobrenzkatechin. Die Reduction des Mononitrobrezkatechin gelingt sehr leicht. Fügt man zu seiner concentrirten wässerigen Lösung Zinn und starke Salzsäure, so findet unter heftiger Erwärmung eine lebhafte Reaction statt. Nach dem Ausfällen des Zinns mit Schwefelwasserstoff, scheidet sich aus der filtrirten und stark concentrirten Flüssigkeit salzsaures Monoamidobrenzkatechin in langen, dunkel gefärbten Nadeln ab, die durch Umkrystallisiren aus verdünnter Salzsäure rein zu erhalten sind. Die Analyse ergab die Zusammensetzung: $\mathrm{C}_{6} \mathrm{H}_{3} \cdot \mathrm{NH}_{2} \cdot\left\{\begin{array}{l}\mathrm{OH} \\ \mathrm{OH}\end{array}+\mathrm{HCl}\right.$.

Will man durch ätzende oder kohlensaure Alkalien die freie Basis ausscheiden, so oxydirt sie sich sofort an der Luft und geht mit violetter Farbe in Lösung.

Ein zweites Nitrobrenzkatechin konnte ich bis jetzt nur in geringer Menge durch die Einwirkung von salpetriger Säure auf eine ätherische Brenzkatechinlösung erhalten. Es ist mit Wasserdämpfen flüchtig, in Wasser schwer löslich und bildet gelbe, ölige Tropfen, die nach einiger Zeit krystallinisch erstarren. 